\title{
Erratum to: Simulation and Optimization of Synchronization Control System for CFETR Water Hydraulic Manipulator Based on AMEsim
}

\author{
Manfen Han • Yuntao Song • Wenlong Zhao • \\ Yong Cheng · Xiang Ji
}

Published online: 20 January 2015

(C) Springer Science+Business Media New York 2015

\section{Erratum to: J Fusion Energ \\ DOI 10.1007/s10894-014-9843-x}

In the original version of this paper, the second and fifthlisted authors are named Yantao Song and Ji Xiang. Their names should appear as Yuntao Song and Xiang Ji.

The online version of the original article can be found under doi:10.1007/s10894-014-9843-x.

M. Han $(\bowtie) \cdot$ Y. Song

University of Science and Technology of China, Hefei 230026,

China

e-mail: hanmanfe@mail.ustc.edu.cn

Y. Song $\cdot$ W. Zhao $\cdot$ Y. Cheng $\cdot$ X. Ji

Institute of Plasma Physics, Chinese Academy of Sciences,

Hefei 230031, China 